\title{
Ringworm on the legs of a patient after long-term intensive care unit residency
}

\author{
Muhammad Ali*, Angelos G. Rigopoulos, Mammad Mammadov, Marios Matiakis and Michel Noutsias \\ Mid-German Heart Center, Department of Internal Medicine III, Division of Cardiology, Angiology and Intensive Medical Care, University Hospital Halle, \\ Martin-Luther-University Halle-Wittenberg, Ernst-Grube-Strasse 40, D-06120 Halle (Saale), Germany
}

\section{Introduction}

Tinea corporis also known as Ringworm is one of the most common fungal infections affect the body [1]. This disease is caused by a group of filamentous fungi commonly known as dermatophytes [2]. This case describes a Ringworm fungal infection with interesting clinical manifestation on the legs of a patient after long-term intensive care unit (ICU) residency.

\section{Case Report}

A 39-year-old female with a four weeks history of admission in the intensive care unit (ICU) our hospital due to acute respiratory distress syndrome (ARDS) caused by Pneumocystis jeroviscii.

Her significant prior medical history included a Non-Hodgkin Lymphoma type B, stage III (Ann Arbor staging) diagnosed and treated since 2015. In the ICU, she received Cotrimoxazole $960 \mathrm{mg} / 250 \mathrm{ml}$ intravenously twice a day for 4 weeks treatment for the primary disease as well as rehabilitation to prevent muscle atrophy. After clinical improvement, the patient was transferred to the normal ward. In the clinical examination follow up we noticed flat brown itchy spots on the skin in her legs. The spots developed a slightly raised border that expanded outward, forming a circular ring. The interior of the spot was clear and smooth (Figure 1).

In this case, the diagnosis of tinea corporis was made by the dermatological consultation on the basis of clinical appearance; neither

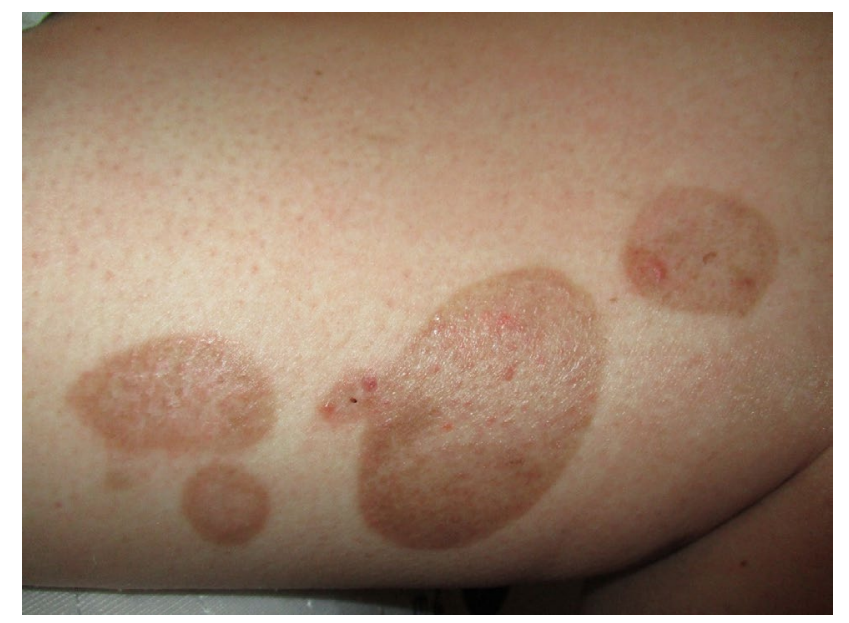

Figure 1. Flat brown itchy spots on the skin in the legs, highly indicative of tinea corporis microscopic nor cultural investigations were performed. The patient was treated with local antimycotics (Selenium sulfide and Ketoconazole $2 \%$ lotions) for 2 weeks. Her dermal spots have improved, and the active rehabilitation was continued.

\section{Discussion}

Tinea corporis is a fungal infection affects the moist skin anywhere on the body. It is so called ringworm because it has red brown rash like appearance. Ringworms are classified according to the body part which is affected. The most common ones are Tinea captis (scalp ringworm), Tinea corporis (skin or body ringworm), Tinea cruris (groin infection), Onychomycosis (Fungal nail infection), Tinea pedis (athlete's foot) [2].The pattern found on feet is called athlete's foot, mild forms of ringworm often respond to antifungal medications. It is very common and three times more common in men than in women [3]. There is no connection between ringworm and worms.

This infection is common worldwide. The fungal kinds responsible for causing tinea capitis diversify according to the geographical region, and may also vary over time [1]. The incidence of Ringworm is more common in males than females; rarely does the disease continue past age sixteen. It occurs in approximately $6 \%$ of the pediatric population; up to one-third of households with contact with an infected person may keep the disease without showing any clinical manifestations [1].

Fortunately, ringworm responds well to home therapy such as: selenium, ketoconazole, or povidone iodine lotion or shampoo [3].

\section{Disclosures}

The authors have no conflicts of interest to disclose. The authors do not have grants or additional technical support to disclose. This article did not receive any specific grant from funding agencies in the public, commercial, or not-for-profit sectors. This manuscript is not under consideration elsewhere and has not been previously published.

${ }^{\star}$ Correspondence to: Muhammad Ali, Department of Internal Medicine III Mid-German Heart Center, Division of Cardiology, Angiology and Intensive Medical Care, University Hospital Halle, Martin-Luther-University HalleWittenberg, Ernst-Grube-Strasse 40, D-06120 Halle (Saale), Germany, Tel: +49 (345) 5573398, E-mail: muhammad.ali@uk-halle.de

Received: May 15, 2019; Accepted: May 22, 2019; Published: May 24, 2019 


\section{References}

1. Taiwo, Oranusi O, Uche S, Adebiyi, Olubunmi M, et al. (2015) Prevalence of tinea (ringworm) infection and associated dermatophytes, in primary schools in Ilorin, North Western Nigeria. J Clin Exp Dermatol Res.
2. Martinez DA, Oliver BG, Gräser Y, Goldberg JM, Li W, et al. (2012) Comparative genome analysis of Trichophyton rubrum and related dermatophytes reveals candidate genes involved in infection. Mbio 3: e00259-e00312. [Crossref]

3. Hainer BL (2003) Review Dermatophyte infections. Am Fam Physician 67: 101-108.

Copyright: (C2019 Ali M. This is an open-access article distributed under the terms of the Creative Commons Attribution License, which permits unrestricted use, distribution, and reproduction in any medium, provided the original author and source are credited. 